Int. J. Electrochem. Sci., 13 (2018) $2286-2298$

\title{
Preparation of Molecularly Imprinted Polypyrrole Modified Gold Electrode for Determination of Tyrosine in Biological Samples
}

\author{
Nihal Ermiş ${ }^{*}$, Nihat Tınkılıç \\ Ondokuz Mayıs University, Faculty of Science and Letters, Department of Chemistry, Samsun, Turkey \\ *E-mail: nihal.ermis@omu.edu.tr
}

doi: $10.20964 / 2018.03 .29$

Received: 5 November 2017 / Accepted: 5 January 2018 / Published: 5 February 2018

\begin{abstract}
In this paper, a novel electrochemical sensor based on molecularly imprinted polypyrrole film at gold electrode for selective and sensitive detection of tyrosine (Tyr) was fabricated. Tyr was used as template molecule and polymerized in presence of pyrrole, used as the functional monomer. As a comparison a non-modified polymer surface was also prepared under same circumstances without template molecule. The feature of both imprinted and non-imprinted electrode surfaces were performed by cyclic voltammetry (CV), square wave voltammetry (SWV) and electro impedance spectroscopy (EIS). The imprinted polypyrrole sensor exhibited good selectivity toward tyrosine in comparison with other structurally similar molecules. Under the optimal experimental conditions, the linearity range and the detection limit of the imprinted sensor were obtained as $5.0 \times 10^{-9}-2.5 \times 10^{-8} \mathrm{M}$ and $2.5 \times 10^{-9} \mathrm{M}$, respectively.
\end{abstract}

Keywords: molecular imprinting, imprinted polymer, polypyrrole, tyrosine

\section{$\underline{\text { FULL TEXT }}$}

(C) 2018 The Authors. Published by ESG (www.electrochemsci.org). This article is an open access article distributed under the terms and conditions of the Creative Commons Attribution license (http://creativecommons.org/licenses/by/4.0/). 